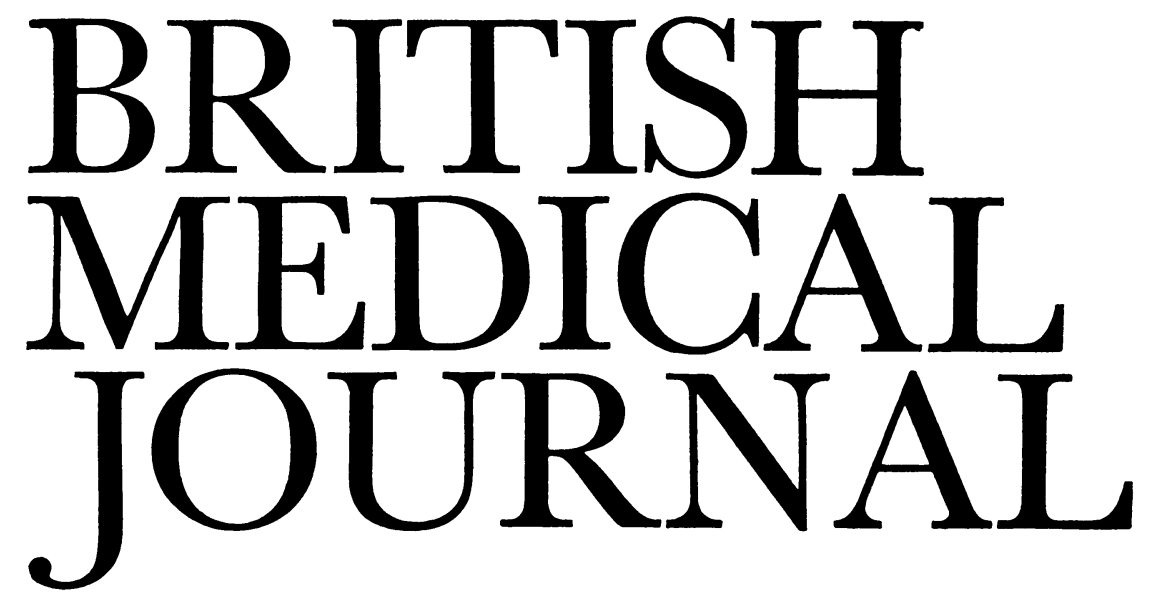

LONDON, SATURDAY 4 APRIL 1981

\title{
Control of chronic pain
}

Chronic pain is now recognised as a disease state and its treatment and management are receiving increasing attention. ${ }^{1-5}$ The treatment of chronic pain should not be confused with terminal care; though connected, they are not synonymous, ${ }^{6}$ ? and in fact most pain is benign. Yet control of pain is mistakenly seen as a specialty. The 3rd World Congress on Pain Relief (to be held in Edinburgh in September) is unlikely to be attended by many general practitioners, general physicians, or surgeons. Simple information on how to control chronic pain needs wide dissemination, with emphasis on what can be done by the consultant in hospital practice and by the general practitioner in the patient's own home.

The first step is for the clinician to accept that there is a problem. Many patients with chronic pain are not helped because of incorrect diagnosis, incorrect drug regimens, and a lack of readiness to use the modern techniques now available. ${ }^{8}$ All too often these patients could be helped by fairly simple measures but are instead left alone to be given repeat prescriptions of medications which were inadequate when first ordered and remain so. Their case sheets or notes tend to be weighed rather than read.

The second step is recognition that diagnosis must come before treatment. For example, is chronic headache due to nephritis, glaucoma, muscle tension, or a leaking aneurysm? Is the sedimentation rate raised, and if so why? Undiagnosed patients can be treated symptomatically but must be kept under review. Standard teaching reminds us that the hypochondriac with a new abdominal pain may have appendicitis, but it is equally true that a sudden exacerbation of pain in a patient with inoperable cancer must be considered equally carefullyis it perhaps another metastasis, an obstruction, a venous thrombosis, or even toothache? Next, we should learn to believe the patient. He or she is the only person actually suffering, so the opinions of doctors, nurses, and relatives on the amount of pain present should be recognised for what they are-guesses. Patients with chronic pain often show inappropriate behaviour, such as the patient with postherpetic neuralgia who smiles while complaining of pain, or the patient with cancer who does not ask for drugs prescribed for use as necessary. This may be due to resignation on the one hand or an unwillingness to disturb the busy nurses on the other. Assessment of pain is difficult in a culture which considers it "manly" not to fuss or complain. The apathy and hopeless misery induced by untreated intractable cancer pain is well known, as is the high incidence of pain in patients with neuroses and psychoses; but doctors still seem reluctant to accept that mood and pain are interrelated, that most pains can be eased by relieving anxiety, and that placebos do work for a time.

A distinction should be made between patients with a normal expectation of life and those with a much shortened one. Narcotic drugs are rarely required and should not be given to patients with chronic benign pain, but if needed should be used without regard to drug addiction in patients with an expectation of life of, say, under two years. How often still are patients with severe intractable pain from cancer refused large doses of narcotics or even any narcotics at all, because of the illusory danger of addiction? Patients with cancer rarely do become addicted, but if they do addiction is a social problem which is meaningless in their circumstances.

Patients need to be educated in how to take their analgesicsnot only to take them regularly but to allow sufficient time for absorption. Thus oral analgesics must be taken regularly, before the pain returns, and never prescribed for use "as required." Allowance should be made for the strength and duration of action of the medication. Prescribing a four-hourly drug six-hourly defeats its object, as does giving too small an injection of a narcotic or switching to a more powerful drug given in too small a dose. The absorption and metabolism of drugs vary from one patient to another and reasonable experimentation with dosage is justifiable.

Patients with a normal expectation of life should have their treatment confined to drugs with at the most a low potential for abuse. In addition to short-acting and long-acting salicylates the non-narcotic analgesic nefopam and buprenorphine may be used because of their long action; they share with pentazocine an absent or low abuse potential.

Depression is a common accompaniment of chronic pain, and specific antidepressants may be needed, but if depression is deep then specialist help must be obtained. Agitation and anxiety will also need control, and if the pattern of pain is fluctuating a drug such as carbamazepine may prove useful. If muscle spasm is a problem then baclofen or orphenadrine may be indicated, as may antispasmodics, antinauseants, and laxatives. Many of the drugs used for these additional problems have analgesic properties of their own and augment the effects of standard analgesics.

These simple drugs are used first for patients with malignant pain; but if it cannot be controlled then narcotics must be used. The use of morphine by mouth has been refined in the 
hospices. ${ }^{7}$ Heroin is still used: its great solubility allows large doses to be given in small volumes, which is of great value in the patient who has lost much flesh. The long half life of methadone increases the risk of accumulation, but given night and morning it produces good background control.

If analgesics are ineffective, destruction of an appropriate neural pathway can provide quick relief of pain. The effect lasts for a variable period-often long enough in patients with malignant pain to cover all or most of their remaining life. The need for the procedure to be repeated makes this approach unsuitable for most patients with chronic benign pain.

Most pain-relief clinics start by reviewing, firstly, the diagnosis and then the drugs used, their dose, and their frequency. Often a psychiatric opinion follows, and, lastly, other treatment is considered. Among the specialised techniques available are destructive methods including coeliac plexus block for upper abdominal pain ${ }^{9}$; subarachnoid phenol for pain in limited spinal dermatome distribution or in perineal pain ${ }^{3}$; percutaneous cervical cordotomy ${ }^{10}$ in unilateral pain below the C5 dermatome; and pituitary injection of alcohol $^{11}$ for cancer pain in any distribution. Benign pain is treated by drugs and non-destructive methods such as peripheral nerve stimulation ${ }^{12}{ }^{13}$; dorsal column stimulation, ${ }^{14}$ useful in phantom limb pain or in arachnoiditis; and acupuncture, ${ }^{15}$ which is another simple stimulation technique with a low (but useful) success rate. Finally, there are biofeedback methods, relaxation techniques, ${ }^{16}$ operant conditioning, ${ }^{17}$ counselling, and other psychiatric methods.

When all these methods have been tried there will still be failures. Such patients should not be turned away without any explanation. Someone must be delegated to spend time talking to the patient before he or she leaves hospital. In the large pain-relief clinic at Walton Hospital, Liverpool, patients of this type are asked at the very least to write in once a year to report what has happened to them, to remind the clinic of their existence, and to ask if there is anything new for their pain. Getting patients to write in ensures two things. Firstly, they will not forget to write-while the hospital might-and, secondly, all patients who write in get an answer (and sometimes a recall). They feel that they are still connected to the hospital and can contact it if their condition deteriorates unexpectedly.

Many years ago, Szasz put the whole problem succinctly: "What is the physician's task in this situation? Whose pain should he control: The patient's? That of his relatives, tortured by the patient's complaints? Or his own, generated by his inability to help the patient ?"18

1 Swerdlow M, Mehta MD, Lipton S. The role of the anaesthetist in chronic pain management. Anaesthesia $1978 ; 33: 250-7$.

2 Bonica JJ, Butler SH. In: Swerdlow M, ed. Relief of intractable pain. 2nd ed. London : Elsevier, 1978:49-64.

${ }^{3}$ Mehta M, ed. Intractable pain. London: WB Saunders Company Ltd, 1973.

${ }^{4}$ Lipton S. Intractable pain, the present position. Hunterian lecture. October 1980. Ann R Coll Surg Engl(in press).

${ }^{5}$ Reuler JB, Girard DE, Nardone DA. The chronic pain syndrome: misconceptions and management. Ann Intern Med 1980;93:588-96.

- Saunders CM, ed. The management of terminal disease. London: Arnold, 1978.

7 Twycross RG, Ventafridda V, eds. The continuing care of terminal cancer patients. Oxford: Pergamon Press, 1980.

${ }^{8}$ Carruthers SG. Clinical pharmacology of pain. In : Smith WL, Merskey $\mathrm{H}$, Gross SC, eds. Pain: meaning and management. Lancaster: MTP Press, 1980:89-103.

- Bridenbaugh LD, Moore DC, Campbell DD. Management of upper abdominal cancer pain. $\mathcal{F} A M A 1964 ; 190: 877-80$.

10 Ganz E, Mullan S. Percutaneous cordotomy. In: Lipton S, ed. Persistent pain: modern methods of treatment. Vol 1. London: Academic Press, 1977:21-33.

11 Moricca G. Pituitary neuroadenolysis in the treatment of intractable pain from cancer. In: Lipton $S$, ed. Persistent pain: modern methods of treatment. Vol 1. London: Academic Press, 1977:149-73.

12 Long DM, Hagfors N. Electrical stimulation in the nervous system: the current status of electrical stimulation of the nervous system for relief of pain. Pain 1975;1:109-23.

13 Natham PW, Wall PD. Treatment of post-herpetic neuralgia by prolonged electrical stimulation. Br Med f 1974 ;iii:645-7.

14 Miles J, Lipton S, Hayward M, Bowsher D, Mumford J, Molony V. Pain relief by implanted electrical stimulators. Lancet 1974 ;i:777-9.

15 Mann F, Bowsher D, Mumford J, Lipton S, Miles J. Treatment of intractable pain by acupuncture. Lancet $1973 ;$ ii :57-60.

${ }^{16}$ Miller N. Applications of learning and biofeedback to psychiatry and medicine. In : Freedman AM, Kaplan HI, Sadock BJ, eds. Comprehensive textbook of psychiatry. 2nd ed. Baltimore: Williams and Wilkins, 1975:349-65.

17 Fordyce WE. Pain viewed as learned behaviour. In: Bonica JJ, ed. International symposium on pain. New York: Raven Press, 1974:415-23.

${ }^{18}$ Szasz TS. The psychology of persistent pain. In: Soulairac A, Cahn J, Charpentier J, eds. Pain. London: Academic Press, 1968:93-113.

\section{After gastrectomy}

In 1885 Billroth removed an antral tumour, closed the cut end of the stomach and the duodenum, and performed an anterior gastrojejunostomy. ${ }^{1}$ Since then all procedures that divert bile and pancreatic secretions across the gastric remnant tend to be labelled "Billroth II" to distinguish them from his earlier operation (1881) of gastroduodenostomy. If eponyms are to be used accurately, however, the operation, still widely practised, that dominated the surgery of duodenal ulcer from the late 1930 s to the late 1960 s - anastomosis of the full width of the open end of the stomach to the jejunum-should be termed the Kronlein procedure. ${ }^{2}$ The third name applied to the operation, Polya, is familiar in Britain because of Polya's persuasive writing ${ }^{3}$ more than 20 years after Kronlein's paper.

Whether termed Billroth II, Kronlein, or Polya, these procedures are highly effective in curing duodenal ulcer. They do so by excluding the ulcer-bearing area, by removing the gastrin-secreting antrum (though its importance in the pathogenesis of duodenal ulcer in man is doubtful), by partially removing acid-secretory cells in the body of the stomach, and by continually bathing those that remain in alkaline secretions. The long-term price for this freedom from recurrence is a small gastric remnant without a sphincter to control its emptying; this may be associated with a complex of vasomotor and other symptoms, generally called "dumping," whose cause is still not entirely clear. A second drawback is the effect of bile on the stomach, which in around $2 \%$ of patients causes bilious vomiting. If this occurs it usually appears early, and in persistent cases can nearly always be cured either by transposing the inflow of bile further down the small gut or by a return to normal continuity with the stomach distanced from the duodenum by a jejunal interposition.

Of possibly greater importance is the prolonged contact of bile with the stomach stump, which leads in time almost invariably either to chronic superficial gastritis or to its successor atrophic gastritis. ${ }^{4}$ Gastritis merges into intestinal metaplasia, which some authorities ${ }^{4}$ believe is a precancerous lesion, though others doubt that the metaplasia is a predictor of cancer. ${ }^{5}$ Certainly in many series there has been an increased incidence of gastric cancer after gastrectomy (especially with gastrojejunostomy), including such surgical horror stories ${ }^{6}$ as the four patients with cancer and three with severe dysplasia out of 108 who had undergone routine gastroscopy more than 20 years previously. A further 12 patients were diagnosed as having moderate dysplasia and no fewer than 52 as having

\section{$\underline{\square}$}

